\title{
Dietary patterns and associated risk factors among school age children in urban Ghana
}

\author{
Deda Ogum Alangea ${ }^{1 *}$ (D), Richmond N. Aryeetey ${ }^{1}$, Heewon L. Gray ${ }^{2}$, Amos K. Laar ${ }^{1}$ and Richard M. K. Adanu ${ }^{1}$
}

\begin{abstract}
Background: Understanding dietary patterns in the study of diet-disease relationships is crucial for designing dietary behaviour interventions. This study aimed to determine associations between dietary patterns and background characteristics among school age children (9-15 years) in Ghana.

Methods: A cross-sectional sample of 487 urban-dwelling children age 9-15 years was recruited using simple random sampling from 24 schools (12 private and 12 public) in the Ga-East Municipality in Southern Ghana. A 7-day food frequency questionnaire was used to record children's consumption of over 100 unique food items. Principal component analyses based on 14 food groups was used to describe emerging dietary patterns (DP). BMl-for-age z-scores segregated by sex were derived using WHO Anthro plus software. Linear regression was used to test associations between 'diet factor' scores, and weight status controlling for age.

Results: Four DPs were identified that explained 53.2\% of variation in the diets of children: (1) energy dense; (2) starchy root staple and vegetables; (3) cereal-grain staples and poultry; and (4) fish \& seafoods. Energy dense DP characterised by processed meat, fried foods, and sugary foods was associated with child overweight/obese status after controlling for age, sex, SES and school type $[F(5,484)=6.868, p<0.001]$. Starchy root with vegetable DP was negatively associated with overweight/obese status, private school attendance and higher SES after controlling for age at bivariate level. However, relationship between 'starchy root staples and vegetables' DP and overweight/obese status lost significance after controlling for other covariates.
\end{abstract}

Conclusion: Our data identified energy-dense dietary pattern to be significantly associated with childhood overweight and obesity. Targeted dietary messages are required to address energy-dense dietary patterns among school-age children.

Keywords: Dietary patterns, Dietary behaviour, School-age children, Ghana, Overweight, Energy-dense

\section{Background}

Nations worldwide are experiencing the nutrition transition which is characterised by rapid urbanisation, industrialisation, trade expansions, changing diets, decreased physical activity and a consequent rise in non-communicable diseases [1-4]. Although most West African countries are in the early stages of this transition, Ghana and other countries like Cape Verde and Senegal are at latter stages [5]. The characteristic changes in diets from traditional foods (less saturated fats and sugars, more whole grains, fruits and vegetables) to more 'westernised diets' (high in saturated fats, protein, refined carbohydrates, simple sugars

\footnotetext{
*Correspondence: dogumalangea@ug.edu.gh

'Department of Population, Family and Reproductive Health, School of

Public Health, University of Ghana, Legon, Ghana

Full list of author information is available at the end of the article
}

and salt) and frequent consumption of fast foods has been observed in non-western societies [5-8].

The changing patterns of food consumption in Ghana has been well documented by Goody and Goody [9]. The major staples grown and consumed in most parts of West Africa, Ghana included are maize, yams, plantains and cassava [9], which are often eaten with soups or stews or used in making porridges or gruels. Over the years, the introduction of rice and other cereal cultivation in most parts of Ghana resulted in increased grain consumption. Typical Ghanaian meals are giving way to continental westernized/Asian alternatives due to inconvenient cooking methods. Plus, these meals need special handling when not eaten immediately. Some local foods with longer shelf-life, like 'gari' (grated, roasted cassava),

(c) The Author(s). 2018 Open Access This article is distributed under the terms of the Creative Commons Attribution 4.0 International License (http://creativecommons.org/licenses/by/4.0/), which permits unrestricted use, distribution, and reproduction in any medium, provided you give appropriate credit to the original author(s) and the source, provide a link to the Creative Commons license, and indicate if changes were made. The Creative Commons Public Domain Dedication waiver (http://creativecommons.org/publicdomain/zero/1.0/) applies to the data made available in this article, unless otherwise stated. 
'1 kenkey' and 'banku' are inconvenient for busy commuting urban dwellers due to the accompanying stews/ soups. This situation is creating increased interest among urban dwellers for processed pre-packaged foods such as sandwiches, biscuits, cheese, noodles, etc. Demand for such foods is also driven by prestige particularly among the middle and high income populations [9]. These unhealthy food options are actually less expensive per calorie compared to healthier options like lean meats, fish, fresh fruits and vegetables [10].

Since 1980, the world has witnessed an 'obesity epidemic' both among adults and children [3]. The number of obese children and adolescents (5-19 years) has risen from 11 million in 1975 to 124 million in 2016, a tenfold increase [11]. There is evidence that overweight and obesity prevalence is accelerating in LMICs including Ghana [12]. Although there is no nationally representative data on weight status of school-age children, prior studies have reported overweight/obesity prevalence between 7.8 and $25.9 \%$ [13-19] in urban Ghana. It is therefore crucial to 'steer the ongoing nutrition transition towards a 'more positive direction' [7] in Ghana; which cannot be achieved in the absence of environmental modifications that encourage and sustain healthier lifestyle changes [20, 21].

Sub-optimal diets have been reported among school-age children and adolescents in developing countries including Ghana [22, 23]. While measurement of actual intakes of nutrients and calories is important, the single-nutrient approach to understanding diet-disease relationships is limited in its ability to account for the complexity of nutrient interactions in free-living individuals [24]. Empirical assessment of dietary patterns of entire diets, therefore, is useful to unravel complex diet-disease relationships. Dietary patterns are also easier for the lay public to relate with and to modify for better health outcomes compared to using nutrients or individual foods. It is therefore important that dietary patterns of school-age children be assessed to aid intervention design and delivery. The promotion of healthy dietary habits in childhood and adolescence would be necessary to prevent diet-related diseases. Intervening at the basic school level is crucial because adoption of unhealthy dietary habits tend to worsen with age in adolescence [25]. Optimal dietary habits in childhood is crucial for the prevention of diet-related diseases in populations since its effects transcends childhood [26]. Benefits of optimal diets include reduced risk of conditions such as anaemia, dental caries, obesity, eating disorders and non-communicable diseases such as cancers, type 2 diabetes, and cardiovascular diseases [27-32].

It is a public health priority globally to identify optimal diets for preventing chronic diseases [33]. Yet, very few studies have assessed empirical dietary patterns among Ghanaians [34, 35] with no published evidence on typical dietary patterns among Ghanaian school-age children. Existing studies have focused on meal consumption patterns or consumption of specific food groups and not an empirical description of patterns in dietary components [23, 36-38]. Dietary patterns in this study is refers to combinations of foods and drinks and their consumption frequencies observed in the population. To the best of our knowledge, this is the first study in Ghana to assess the dietary patterns of school age children in Urban Ghana. The objective of this paper is to empirically assess dietary patterns of school-age children 9-15 years and investigate their relationship with a priori determined child background characteristics (age, sex, socio-economic status, school type and weight status) in urban Ghana.

\section{Methods}

\section{Study design, population and setting}

A cross-sectional design was used to assess the dietary behaviour and food consumption patterns of basic school pupils aged 9-15 years. Participants were enrolled from both private $(n=12)$ and public $(n=12)$ schools in the Ga-East Municipality of the Greater Accra Region of Ghana. Participating schools had both primary and Junior high school departments. The Ga-East Municipality is one of 16 administrative districts of the Greater Accra Region which contains the nation's capital, Accra.

\section{Sampling procedure and technique}

The ability of children to adequately identify foods and recall dietary information is age-dependent. Thus, the minimum age for participating pupils was 9 years in accordance with recommendations regarding ageappropriateness of available dietary assessment methods [39]. The minimum sample size of 448 estimated was based on a pupil population of 50,200; expected frequency of obesity of $10 \%$, assuming a least expected prevalence of $7 \%$ and a non-consent rate of $15 \%$. A sample proportional to the size of each school was selected to make up a total sample size of 500 pupils. A total of 487 pupils eventually participated in the dietary assessment.

The full list of basic schools within the district was obtained from the Ghana Education Service (GES). Simple random sampling (balloting technique) was used to select 12 private and 12 public schools from a total of 80 (47 public and 37 private) registered basic schools (having both primary and Junior High School (JHS)) in the municipality. Within each school, balloting without replacement was used to select eligible pupils: Ballot bowls (separate coloured for boys and girls) containing pre-labelled ('yes' or 'No') ballot papers equivalent to the number of pupils on roll for specific research day were moved round 
primary classes 4 to JHS 3 by research assistants for pupils to pick. Selected pupils were given a written informed consent form to obtain parental consent. Completed consent forms were submitted to class teachers and subsequently collected by research team. Pupils who received parental consent also needed to complete an assent form to indicate child's willingness to participate. As part of the assent process, the objectives, risks/benefits, costs and procedures of the study were explained to the children in their preferred language (English, Twi or Ga).

\section{Study measures and data collection procedures Demographic characteristics}

Child's age in completed years; type of school (public versus private), educational level completed by mother/ caregiver; residential status; and household ownership of assets (car, refrigerator/freezer, television, DVD/VCD player, computer, gas/electric stove and air conditioners).

\section{Food frequency and dietary patterns}

A 7-day Food frequency questionnaire (FFQ) (see Additional file 1) was used to record usual consumption data on a range of foods (about 100 unique food items). This FFQ was designed specifically for this study group and used in an earlier study among a larger population of Ghanaian school-age children [40]. Consumption of food items/sub-groups were indicated as the summation of the number of times each constituent food item(s) were consumed within the past 7 days. Factor scores for each identified pattern from PCA were saved for use in liner regression procedures.

\section{Height and weight}

Standing height was measured using the Charder HM200P portable stadiometer (Charder Electronic co., Ltd., Taichung, Taiwan) to the $0.1 \mathrm{~cm}$. Body weight was measured with a portable Seca electronic weighing scale (SECA, Hamburg, Germany) to the nearest $0.1 \mathrm{~kg}$.

Twelve research assistants were trained on how to administer the questionnaires and collect nutrition data as well as observe ethical procedures regarding research involving children. The study tools were pre-tested in two non-participating schools that had both primary and JHS departments within the school district. Study tools were interviewer-administered and lasted between $30 \mathrm{~min}$ and $1 \mathrm{~h}$.

The research assistants probed for daily and weekly consumption as well as mixed meal options to help children with recall. Additionally, pupils were encouraged to indicate if they consumed foods that were not identified in the list of foods provided.

Measurement of weight $(\mathrm{kg})$ and standing height $(\mathrm{cm})$ was carried out following standard procedures for both weight and height measurements adapted from Shorr [41]. All measurements were taken at school with participants wearing their usual school uniform but without foot wear, socks, watches, and items in pocket or any heavy clothing like jacket or sweater. Interference of complex hairstyles with height measurements were reduced by encouraging participants to let hair down when possible and or by firmly pushing the head piece of height rod to compress hair. All anthropometric measurements were taken in duplicate. The same research assistants who administered the questionnaires were trained to take weight and height measurements of participants.

\section{Data analysis}

Data were entered using a Microsoft access (2007 version) database, with activated checks to reduce errors. IBM SPSS version 20 software was used for data analysis. Frequency distributions were summarized in tables for categorical demographic characteristics. Arithmetic mean was determined for respondent age. Preliminary tests were carried out on data to check for normality/ distribution (z- scores for outliers, Kolmogorov Smirnov test, Q-Q plots) and also reliability test (Cronbach's alpha test statistic) performed on items included in Principal Component analyses (PCA).

Age (years) of respondents was grouped into the following categories: 9 to 10 years, 11 to 12 years and 13 to 15 years age groups); sex of pupil (either male or female); school administration type and household socio-economic status (SES) of respondents. Household SES was ascertained using principal component analysis. The factor score based on ownership of 8 items (car/ vehicle, house, television, refrigerator, gas/electric cooker, DVD/VCR/video player, air conditioner, and satellite dish) was used to group respondents into rich, middle and poor households [42]. Respondents were classified as overweight/obese or non-overweight/obese based on their BMI-for-age and sex (BMA) z-score. Overweight and obesity was defined as BMI for age-and -sex z-score $(\mathrm{BMA})>1$ SD and $\geq 2 \mathrm{SD}$ respectively; normal (nonobese/overweight) was defined as BMA $\leq 1$ SD [43]. For the purposes of this study, pre-obese and obese groups were considered together in one group known as "overweight" and used for tests of associations.

Dietary patterns were assessed using PCA based on data collected with FFQ. In order to ensure that $>5 \%$ of respondents consumed each food item included in PCA, food items were categorized into several sub-groups based on shared nutritional value/significance. Subgroups of foods (see Additional file 2) created for PCA are: processed meats; spreads and toppings; fried foods; cocoa beverages and Dairy; high caloric foods; poultry and eggs; starchy roots\& tubers; sugar sweetened 
beverages; fruits and fruit juices; vegetables and soups; meats (all non-poultry meats); cereals/grains; legumes \& nuts; and fish and sea foods. Thus, a total of 14 items were subjected to PCA in order to identify foods highly correlated with each other and possibly combined to describe the major patterns in respondent diets. PCA used orthogonal rotation (varimax) and number of components determined by Kaiser's stopping rule (factors with Eigen values over 1.0 are considered in analysis) (Kaiser [44]) and examination of scree plots. Varimax rotation was used to maximize the factor loadings onto each component to allow ease of interpretation of patterns. Patterns were defined based on factor loadings $>0.4$ and $<-0.4$. In order to assess suitability of data for factor analysis, acceptable cut-offs for the Kaiser-Meyer-Olken (KMO) Measure test and Bartlett's test of sphericity were used. Dietary patterns derived from PCA were appropriately labeled to reflect the constituents of each isolated component accounting for variation in diets. A dietary pattern, thus, refers to a distinguishable set of highly correlated food items as extracted in PCA.

Simple linear regression, controlling for age, was used to test the association between dietary pattern factor scores and child sex, weight status, school type and household SES. Sensitivity analyses showed that age used in continuous form or categorical form showed no significant changes in level of significance of associations between DPs and covariates. Thus, age was used in the categorical form in analyses. Multiple linear regression was performed to determine significant factors associated with each of the four dietary patterns. An alpha level of 0.05 was used to determine statistical significance.

\section{Results}

\section{Demographic characteristics}

The mean age of pupils was 12.1 years $(\mathrm{SD}=1.5)$ with about $15 \%$ of them in the age $9-10$ years category. Females were slightly more than males (53.6 vs. 46.4); about three-fifths of the sample were public school pupils (see Table 1).

\section{Emerging dietary patterns}

Results of PCA yielded a $\mathrm{KMO}=0.85$ which is meritorious (Field, 2009). Additionally, the items used had sufficiently large correlations for PCA (Bartlett's test of sphericity $\left.=\chi^{2} \quad(91)=1328.16, p<0.001\right)$. Furthermore, the 14 items used in the PCA showed good consistency (Cronbach's alpha $=.78$ ). Number of components decided upon was informed by an examination of the scree plot, which showed an inflection at the fifth component. PCA identified four dietary patterns that explained 53. $2 \%$ of the variance in diets of respondents (see Table 2). The label assigned to components was based on the items with high loadings within each component as well
Table 1 Demographic characteristics of School Age Children in Ghana who participated in study $(N=487)$

\begin{tabular}{lll}
\hline Characteristic & Frequency & Percent \\
\hline Age group & 73 & 15 \\
9-10 years & 213 & 43.7 \\
11-12 years & 201 & 41.3 \\
13-15 years & & \\
School category & 189 & 38.8 \\
$\quad$ Private & 298 & 61.2 \\
Public & & \\
Sex & 226 & 46.4 \\
Male & 261 & 53.6 \\
Female & & 40.9 \\
Household Socio-economic status & \\
Poor & 199 & 38.4 \\
Middle & 187 & 20.7 \\
Rich & 101 & 17.7 \\
BMl status & & 82.3 \\
Overweight/Obese & 86 & \\
Non-Overweight/obese & 401 & \\
\hline
\end{tabular}

atertiles of wealth index computed using: (ownership of car/ vehicle, house, television, refrigerator, gas/electric cooker, DVD/NCR/video player, air conditioner, and satellite dish) poor $=$ lowest $40 \%$; middle $=$ middle $40 \%$; Rich $=$ top $20 \%$

as interpretability of factors. These included: (1) Energy dense; (2) starchy roots and vegetable/ 'typically Ghanaian'; (3) cereal-grain and poultry/ 'modern Ghanaian'; and (4) 'fish and seafood-based' diets. Table 3 shows the various food items and the truncated components solution.

\section{Associations between major dietary patterns and pupils characteristics}

Table 3 presents the four major dietary patterns emerging from the survey of basic school pupils age 9-15 years in urban Ghana. The first pattern "Energy dense" diet explaining $21.6 \%$ of the variation in diets of pupils was associated with higher household SES $[\mathrm{F}(2,482)=13.182$, $p<0.001]$, child overweight $[\mathrm{F}(2,482)=5.185, p<0.01]$ and private school attendance $[\mathrm{F}(2,482)=7.183, p=0$. 001]. Consumption of energy dense diets was not significantly associated with sex or age of child in bivariate analyses. After controlling for child age, sex, school type and household SES, the association between consumption of energy dense diet and child overweight status remained significant $[F(5,479)=6$. 868, $p<0.001]$. Details of bivariate and multivariate linear regressions of dietary patterns and background factors are shown in Tables 4 and 5 respectively. 
Table 2 Dietary patterns of school age children determined using principal component analysis

\begin{tabular}{|c|c|c|c|}
\hline Component & & $\%$ of variance & Label for dietary pattern \\
\hline \multirow[t]{7}{*}{ Component 1} & Sugar-sweetened beverages, & 21.6 & Energy dense pattern \\
\hline & Fried foods & & \\
\hline & Processed meats & & \\
\hline & Spreads and toppings & & \\
\hline & Fruits and fruits juices & & \\
\hline & Cocoa beverages and dairy products & & \\
\hline & High calorie snacks & & \\
\hline \multirow[t]{5}{*}{ Component 2} & Meats (all non-poultry, non-sea food) & 13.7 & Starchy roots and vegetables/ typically Ghanaian \\
\hline & starchy roots and tubers & & \\
\hline & Vegetables* & & \\
\hline & Legumes & & \\
\hline & Soups & & \\
\hline \multirow[t]{4}{*}{ Component 3} & Cereals/grains & 10.4 & Cereal-grain and poultry/ modern Ghanaian \\
\hline & Poultry and eggs & & \\
\hline & Vegetables* & & \\
\hline & Soups & & \\
\hline Component 4 & Fish and sea foods & 7.4 & Fish and sea food \\
\hline
\end{tabular}

Note: 'wewre' refers to sun-dried wild melon seeds used for soups or stews

*excludes tomatoes, peppers and onions since they are basic ingredients in every Ghanaian hot meal

The second pattern, "starchy roots \&vegetable-based diet", which is 'typically Ghanaian', explained $13.7 \%$ of variation in pupil diets and was negatively associated with overweight status $[\mathrm{F}(2,482)=7.369, p=0.001]$. It was also associated with older age groups $[\mathrm{F}(1,483)=$ 10.091, $p=0.002]$, public school attendance $[\mathrm{F}(2,482)=$ 12.702, $p<0.001]$ and lower household $\operatorname{SES}[\mathrm{F}(2,482)=$ 8.725, $p<0.001$ ] categories. After controlling for age, sex, school type and household SES, consumption of the 'starchy root \& vegetable diet' was no longer associated with child weight status. However, the starchy roots \&vegetable-based diet was significantly associated with public school attendance and older age groups after controlling for household SES, age and weight status $[F(5,479)=5.868, p<0.001]$.

The third DP was negatively associated with private school attendance at the bivariate stage $[F(2,482)=3$. 059, $p<0.05]$. Both the third and fourth identified

Table 3 Sub-food group items and their truncated components solution

\begin{tabular}{|c|c|c|c|c|c|}
\hline Food items & DP 1 & DP 2 & DP 3 & DP 4 & $h^{2}$ \\
\hline Sugar sweetened beverages (SSB) & 0.680 & 0.173 & -0.090 & -0.102 & 0.512 \\
\hline High calorie snacks (including sweets \& pastries) & 0.680 & 0.270 & 0.042 & -0.005 & .538 \\
\hline Cocoa beverages, milk and dairy & 0.638 & -0.045 & 0 & -0.203 & 0.450 \\
\hline Processed meat & 0.592 & -0.012 & 0.160 & 0.201 & 0.416 \\
\hline Fruits and fruit juices & 0.592 & 0.365 & 0.066 & -0.056 & 0.491 \\
\hline Spreads and toppings & 0.585 & 0.189 & 0.136 & 0.192 & 0.434 \\
\hline Fried foods & 0.579 & 0.255 & 0.377 & 0.041 & 0.544 \\
\hline Legumes (pulses and nuts) & 0.206 & 0.659 & -0.031 & -0.016 & 0.477 \\
\hline Meat (non-poultry) & 0.117 & 0.658 & 0.123 & 0.084 & 0.468 \\
\hline Starchy roots and plantains & 0.075 & 0.645 & 0.045 & -0.056 & 0.427 \\
\hline Vegetables and soups & 0.136 & 0.533 & 0.409 & 0.018 & 0.471 \\
\hline Cereals & -0.051 & 0.081 & 0.854 & -0.080 & 0.745 \\
\hline Poultry and eggs & 0.483 & 0.101 & 0.584 & 0.047 & 0.586 \\
\hline Fish and sea food & -0.014 & -0.006 & -0.058 & 0.937 & 0.882 \\
\hline
\end{tabular}

$\mathrm{H}^{2}$ refers to communality; italicised entries are items contributing significantly to each PCA component 
Table 4 Bivariate tests of associations between emerging dietary patterns and background characteristics

\begin{tabular}{|c|c|c|c|c|c|c|c|c|c|c|c|c|}
\hline \multirow[b]{2}{*}{ Variables } & \multicolumn{2}{|c|}{ Energy-dense } & \multirow[b]{2}{*}{$\beta$} & \multicolumn{3}{|c|}{ Starchy roots \&vegetable } & \multicolumn{3}{|c|}{ Cereal-grains \& poultry } & \multicolumn{2}{|c|}{ Fish \& seafood } & \multirow[b]{2}{*}{$\beta$} \\
\hline & $B$ & SE B & & $B$ & SE B & $\beta$ & $B$ & SE B & $\beta$ & $B$ & $S E B$ & \\
\hline Age & -0.074 & 0.064 & -0.052 & 0.203 & 0.064 & $0.143^{* *}$ & -0.094 & 0.064 & -0.067 & 0.043 & 0.065 & 0.030 \\
\hline Sex (female) & 0.106 & 0.091 & 0.053 & 0.002 & 0.090 & 0.001 & 0.103 & 0.091 & 0.052 & -0.114 & 0.091 & -0.05 \\
\hline Private school & 0.343 & 0.095 & $0.167^{* * *}$ & -0.364 & 0.094 & $-0.178^{* * *}$ & -0.191 & 0.096 & $-0.093^{*}$ & 0.009 & 0.096 & 0.004 \\
\hline Overweight & 0.355 & 0.118 & $0.136^{* *}$ & -0.251 & 0.118 & $-0.096^{*}$ & -0.113 & 0.119 & -0.043 & 0.081 & 0.119 & 0.031 \\
\hline Household SES ${ }^{a}$ & -0.293 & 0.059 & -0.222 & 0.159 & 0.059 & $0.121^{* *}$ & 0.090 & 0.060 & 0.069 & 0.014 & 0.06 & 0.010 \\
\hline
\end{tabular}

$B$ beta coefficient, $\beta$ standardized beta coefficient

${ }^{*} p<.05$

${ }^{* *} p<.01$

*** $p<.001$

${ }^{\text {a }}$ from rich towards poor SES groups; associations adjusted for age only

dietary patterns were not significantly associated with any of the child background characteristics examined in this study in multivariate analyses.

A multiple logistic regression examining the relationship between child weight status and the four identified dietary patterns controlling for age, sex, school type and household SES showed a positive association between energy dense pattern and child overweight $(\mathrm{AOR}=1.34$, $95 \% \mathrm{CI}=1.04-1.70)$. Male sex was significantly associated with reduced odds of being overweight $(\mathrm{AOR}=0$. $41,95 \% \mathrm{CI}=0.24-0.69)$ after controlling for age, school type, household SES and dietary pattern. Childhood overweight was not significantly associated with any of the other three dietary patterns.

\section{Discussion}

This study aimed to describe the dietary patterns emerging from food consumption data of school age children in urban Ghana. Four main food consumption patterns were identified: energy dense; starchy roots and vegetables; grain-based and poultry; and fish/seafoods. Both the healthy and unhealthy food patterns were associated with child age and household socioeconomic status.

\section{Major dietary patterns emerging from consumption data}

The first major dietary pattern (DP), "energy dense" identified in this study was characterized by the consumption of sugar sweetened beverages, candies, ice creams, fried foods, processed meats, spreads, toppings, and snacks like cakes, pies, doughnuts and other savory foods. This diet pattern typically referred to as the "westernized diet" has been identified in other non-western societies including Ghana, probably due to industrialization and global food market expansion $[3,45,46]$. This DP has also been seen in almost all studies that sought to examine dietary patterns among children and adolescents elsewhere [47-49]. Food items associated with the energy dense pattern have been reported elsewhere, although sometimes split into different but related components. For instance, Pala et al. [47] identified two energy dense patterns labeled "snacking" and "sweet and fat" which together explained most $(16 \%)$ of the variability in the diets of European children. Also, Correa et al. [50] described a similar pattern as "Brazilian industrialized". Findings of this study agrees with the body of evidence linking energy-dense DP consumption and overweight/obesity among children [48, 51, 52]. However, Pala et al. [47] found no association between energy dense DPs and overweight status among European children

Table 5 Multivariate analyses of background factors associated with emerging dietary patterns

\begin{tabular}{|c|c|c|c|c|c|c|c|c|c|c|c|c|}
\hline \multirow[b]{2}{*}{ Variables } & \multicolumn{2}{|c|}{ Energy-dense } & \multirow[b]{2}{*}{$\beta$} & \multicolumn{3}{|c|}{ Starchy roots \&vegetable } & \multicolumn{3}{|c|}{ Cereal-grains \& poultry } & \multicolumn{2}{|c|}{ Fish \& seafood } & \multirow[b]{2}{*}{$\beta$} \\
\hline & $B$ & SEB & & $B$ & SE B & $\beta$ & $B$ & SEB & $\beta$ & $B$ & SEB & \\
\hline Age & -0.021 & 0.065 & -0.015 & 0.138 & 0.065 & $0.097^{*}$ & -0.13 & 0.067 & -0.091 & 0.049 & 0.067 & 0.035 \\
\hline Sex & 0.046 & 0.09 & 0.023 & 0.045 & 0.09 & 0.023 & 0.127 & 0.092 & 0.064 & -0.126 & 0.093 & 0.063 \\
\hline Private school & 0.153 & 0.104 & 0.075 & -0.301 & 0.105 & $-0.147^{* *}$ & -0.154 & 0.107 & -0.075 & 0.018 & 0.107 & 0.009 \\
\hline Overweight & 0.246 & 0.119 & $0.094^{*}$ & -0.189 & 0.119 & -0.072 & -0.099 & 0.122 & -0.038 & 0.112 & 0.123 & 0.043 \\
\hline Household SES ${ }^{a}$ & -0.229 & 0.065 & $-0.174^{* * *}$ & 0.064 & 0.065 & 0.049 & 0.046 & 0.067 & 0.035 & 0.022 & 0.067 & 0.017 \\
\hline$R^{2}$ & & & 0.067 & & & 0.058 & & & 0.008 & & & 0.006 \\
\hline$F$ & & & 6.868 & & & 5.868 & & & 1.783 & & & 0.578 \\
\hline
\end{tabular}

$B$ Beta coefficient, $\beta$ standardized beta coefficient

${ }^{*} p<.05$

${ }^{* *} p<.01$

${ }^{* * *} p<.001$

afrom rich towards poor SES groups 
in a longitudinal study. Energy dense DP, was significantly associated with higher SES and its' proxy, private schools; the relationship remained significant after controlling for all background characteristics. The association between higher SES groups and 'unhealthy' dietary behaviours has been typically reported in Ghana and other developing countries, but contrary to developed country situations. For instance, Craig et al. [48] reported energy dense DP among lower SES groups while healthier DPs were associated with children belonging to higher SES groups. This disparity between developing and developed countries regarding the link between SES and health outcomes is well documented as a function of countries' overall GDP [53] and will eventually shift towards lower SES groups over time. Nevertheless, the negative effects of energy dense diets on child weight status in Ghana, irrespective of SES, suggests need for interventions to control consumption of energy dense DPs.

The second (starchy roots and vegetable) and third (cereal-grain and poultry) DPs identified in this study both include the consumption of staples typically available in Ghana. However, there are differences in consumption due to the changing diets of Ghanaians as documented by Goody and Goody [9]. Foods in the third DP are likely more 'prestigious' and less labour intensive compared to those in the third DP. Additionally, foods in the grain-cereal and poultry DP are increasingly made available in school canteens and sold by food vendors as they are generally more appealing to children. Meanwhile, foods in the starchy roots and vegetables' DP are generally more affordable and can be accessed easily from vendors outside of the school. It is therefore not surprising that the consumption of the second DP was associated with lower SES groups, older age of child, and public-school attendance. Considering that only 5\% of pupils in a previous study brought food daily from home [54], sourcing of food from the school and its' environs remains inevitable. Also, the likelihood that parents will pack traditional meals (like kenkey, banku, kokonte, gari, $e b a$, rice ball, $\left.{ }^{3} \mathrm{fufu}\right)$, which are served with soups and vegetables is low due to the inconvenience (possible spills and requires skill to eat without stains) and low prestige associated with traditional foods. The soups and stews served with these typically Ghanaian foods are also highly perishable and there are food safety concerns about packing it for children. Consequently, younger aged children will consume more foods in the third DP, grains and chicken compared to the older children who will may patronize local foods they have developed preference for at school. While this study did not assess the usual sources of staple foods, anecdotal evidence suggests that these typically Ghanaian foods are more likely to be consumed at home with family during supper on school days or anytime on weekends. Thus, children living in homes that do not cook meals frequently, will generally record lower consumption of DP 2 and a higher consumption of DP 3.

Although studies among European children found a protective effect of DP based on whole grains, legumes and vegetables [47] on weight, this study did not find significant associations between the third DP and SES, age, school type and weight status of children. This finding must be interpreted with caution since the relationship is likely influenced by nature of data collected. Our study questionnaire did not discriminate between whole and refined cereal/grain consumed by the children. Again, the poultry consumed in this DP with cereals is most likely fried and or stewed, considering how grainsbased meals are typically served (both at home and school) or sold in Ghana.

The last DP, "fish and sea foods" explained 7.4\% of the variation in the diets of the children surveyed and was not associated with any child characteristic. While it is not normal for fish and seafoods alone to be consumed in any diet, this sub-food group recorded the highest communality (.882) compared to the remaining 15 items used in PCA, suggestive of relevance. Craig and colleagues [48] identified "fish and sauce" DP among children 5-11 years old in Scotland. The consumption of fish as part of a healthy diet is beneficial [55]. Fish is widely consumed in Ghana $[8,56]$ and most often served whole (with head and bones) irrespective of cooking method. It is possible that the skill required to eliminate bones as well as other factors may influence both parent and children's' from choice of fish compared to 'easier to consume' options like eggs or poultry. An assessment of fish consumption by school-age children may provide evidence required to understand its inclusion in diets and how it relates with weight status.

To our knowledge, this is the first study to identify dietary patterns in the diets of school-age children in Ghana. We agree that this study is cross-sectional and thus, causality cannot be assumed for the observed association between energy dense dietary pattern consumption and child overweight/obese status. Nevertheless, the identification of dietary patterns similar to those found in other studies is a contribution to knowledge regarding the public health goal of identifying optimal dietary patterns across settings.

A limitation of this study is the inability of data collected on cereal grains to distinguish between refined and unrefined grains consumed. The researchers felt that it would be nearly impossible for children to provide this detail for all grains eaten in and out of the home. This anticipated difficulty is also due to the possibility of these grains to be masked when cooked in a composite meal like "jollof rice" or "Wakye', which are popularly consumed forms among children. Also, grains available 
in Ghana are mostly whole grain with the exception of rice and maize which have polished versions. Nevertheless, we believe that this had no significant influence on the major dietary patterns identified among the children. Secondly, our classification of households based on possession of 8 assets may have oversimplified or poorly ranked households. Nevertheless, the use of household assets in ranking households in this setting is reliable [42]. Lastly, we acknowledge that no single dietary assessment method, including the FFQ, is able to perfectly assess dietary exposure. Nevertheless, the FFQ when specifically designed for target groups, remains the tool of choice in measuring usual intakes of populations [57].

\section{Conclusions}

This study identified four dietary patterns; with the unhealthy pattern significantly associated with overweight/ obesity, higher household SES and older age groups. This has implications for later health outcomes because dietary habits are likely to worsen in older adolescence [26]. Adolescence is a critical period for establishing lifetime dietary patterns and if a significant component of their diet are energy-dense-low nutrient options, it imposes extra risk of poor nutrition and adverse health outcomes. The evidence shows the existence of both traditionally available healthy foods as well as foods typical of 'western among Ghanaian school age children (9-15 years). This provides an opportunity for promoting more healthful food choices especially among middle and higher SES groups during health promotions.

\section{Endnotes}

${ }^{1}$ Kenkey is boiled fermented corn dough balls wrapped in corn husks; can be mashed and sweetened with sugar and enjoyed alone or with bread, or balls eaten with hot sauce, soup or stew

${ }^{2}$ Banku is made from fermented corn dough mixed with fermented cassava dough. The paste is stirred over heat to solidify, made into balls and served with pepper sauce, soups or stews

${ }^{3} \mathrm{Fufu}$ is cooked starchy roots or tubers that have been pounded into a smooth paste; usually eaten with soup

${ }^{4}$ Wakye is rice and beans cooked together

\section{Additional files}

Additional file 1: 7-day Food Frequency Questionnaire. (DOCX $21 \mathrm{~kb}$ ) Additional file 2: Food items defined under specific sub-food groups used in the PCA. (DOCX $15 \mathrm{~kb}$ )

\section{Abbreviations}

BMA: BMI for Age and Sex; DP: Dietary pattern; FFQ: Food frequency questionnaire; JHS: Junior High School; PCA: Principal component analysis; SES: Socio Economic Status

\section{Acknowledgements}

The authors gratefully acknowledge support received by the first author from the University of Ghana Building A New Generation of Academics in Africa (BANGA-Africa) project with funding from the Carnegie Corporation of New York. We also acknowledge the contribution of all Research assistants, participating children, parents and head-teachers without whom this data would not be available.

\section{Funding}

This study was funded by DANIDA Building Stronger Universities Platform for Human Health program as well as the University Of Ghana College Of Health Sciences Post-Graduate Fellowship. All funding received were used to support field data collection.

\section{Availability of data and materials}

The Dataset used for this paper is available from corresponding author upon reasonable request.

\section{Authors' contributions}

DOA, RNA, AL, RMA designed the study and collected data; DOA and HLG analysed data and interpreted results; DOA wrote manuscript; DOA, RNA, AL, RMA and HLG made significant contributions to writing of manuscript, made critical revisions of the manuscript for important intellectual content and approved final draft.

\section{Ethics approval and consent to participate}

Ethical Clearance was obtained from the Institutional Review Board (IRB) of the Noguchi Memorial Institute for Medical Research with reference number NMIMR-IRB CPN 102/11-12. Additional permissions were obtained from the Ghana Education Service (both from Director General's department and the Ga-East Municipal Director of Education) and heads of selected schools before any contact was made with pupils. Consent forms explaining study objectives, procedure, confidentiality, benefits and voluntary nature of study were given to pupils to take home to seek parental approval. Each pupil also signed an assent form before participation after receiving parental consent. This method of obtaining parental consent for child's participation was approved by the ethics board. All field tools had unique Identification numbers which were used on forms and during data entry. Thus, responses cannot be linked to participating individuals in the study.

\section{Competing interests}

The authors declare that they have no competing interests.

\section{Publisher's Note}

Springer Nature remains neutral with regard to jurisdictional claims in published maps and institutional affiliations.

\section{Author details}

${ }^{1}$ Department of Population, Family and Reproductive Health, School of Public Health, University of Ghana, Legon, Ghana. ${ }^{2}$ Department of Community and Family Health, College of Public Health, University of South Florida, Tampa, USA.

Received: 20 December 2017 Accepted: 1 May 2018

Published online: 10 May 2018

References

1. Popkin BM. The nutrition transition: an overview of world patterns of change. Nutr Rev. 2004;62:S140-3.

2. Popkin BM. The nutrition transition in the developing world. Devel Policy Rev. 2003;21:581-97.

3. Popkin BM, Adair LS, Ng SW. Global nutrition transition and the pandemic of obesity in developing countries. Nutr Rev. 2012;70:3-21.

4. Popkin BM, Duffey K, Gordon-Larsen P. Environmental influences on food choice, physical activity and energy balance. Physiol Behav. 2005;86:603-13.

5. Bosu WK. An overview of the nutrition transition in West Africa: implications for non-communicable diseases. Proc Nutr Soc. 2015;74:466-77.

6. Abrahams Z, Mchiza Z, Steyn NP. Diet and mortality rates in sub-Saharan Africa: stages in the nutrition transition. BMC Public Health. 2011;11:801.

7. Vorster $\mathrm{HH}$, Kruger A, Margetts BM. The nutrition transition in Africa: can it be steered into a more positive direction? Nutrients. 2011;3:429. 
8. Ecker O, Fang P. Economic development and nutrition transition in Ghana: taking stock of food consumption patterns and trends, Achieving a nutrition revolution for Africa: the road to healthier diets and optimal nutrition; 2016. p. 28-50.

9. Goody J, Goody E. Food and identities: changing patterns of consumption in Ghana. Cambridge Anthropology. 1995;18(3):1-14. Retrieved from http:// www.jstor.org/stable/23818753. It was published by Berghahn Books, Oxford.

10. Drewnowski A, Darmon N. Food choices and diet costs: an economic analysis. J Nutr. 2005;135:900-4.

11. WHO. New global estimates of child and adolescent obesity released on world obesity day. World Health Organisation; 2017. http://www.who.int/ end-childhood-obesity/news/new-estimate-child-adolescent-obesity/en/.

12. Abarca-Gómez L, Abdeen ZA, Hamid ZA, Abu-Rmeileh NM, Acosta-Cazares $B$, et al. Worldwide trends in body-mass index, underweight, overweight, and obesity from 1975 to 2016: a pooled analysis of 2416 population-based measurement studies in 128. 9 million children, adolescents, and adults. Lancet. 2017;390:2627-42.

13. Mohammed H, Vuvor F. Prevalence of childhood overweight/obesity in basic school in Accra. Ghana Med J. 2012;46:124.

14. Ghana School Survey. Nutrition and obesity report of the Ghana school survey results dissemination workshop, September 2012. Accra: Department of NUtrition and Food Science, University of Ghana and School of Human Nutrition and Dietetics, McGill University, Montreal; 2012.

15. Abachingsa $C$. The prevalence of obesity among school-going children in Achimota-Legon area. Legon: University of Ghana, Legon; 2001. [Dissertation]

16. Mogre V, Gaa PK, Abukari RN. Overweight, obesity and thinness and associated factors among school-aged children (5-14 years) in Tamale, Northern Ghana. Eur Sci J. 2013;9(20).

17. Kwaw E, Sackey AS, Awere E. Assessment of the nutritional status of junior high school students-evidence from Mfantseman municipality of Ghana. Science. 2013;1:222-6.

18. Amidu N, Owiredu W, Saaka M, Quaye L, Wanwan M, et al. Determinants of childhood obesity among basic school children aged 6-12 years in Tamale Metropolis. J Med Biomed Sci. 2013;2:26-34.

19. Manyanga T, El-Sayed H, Doku DT, Randall JR. The prevalence of underweight, overweight, obesity and associated risk factors among school-going adolescents in seven African countries. BMC Public Health. 2014;14:887.

20. Story M, Kaphingst KM, Robinson-O'Brien R, Glanz K. Creating healthy food and eating environments: policy and environmental approaches. Annu Rev Public Health. 2008:29:253-72.

21. Hawkes C, Smith TG, Jewell J, Wardle J, Hammond RA, et al. Smart food policies for obesity prevention. Lancet. 2015;385:2410-21.

22. Ochola S, Masibo PK. Dietary intake of schoolchildren and adolescents in developing countries. Ann Nutr Metab. 2014;64(suppl 2):24-40.

23. Abiba A, Grace ANK, Kubreziga KC. Effects of dietary patterns on the nutritional status of upper primary school children in Tamale metropolis. Pak J Nutr. 2012;11:591-609.

24. Hu FB. Dietary pattern analysis: a new direction in nutritional epidemiology. Curr Opin Lipidol. 2002;13:3-9.

25. Llich JZ, Brownbill RA. In: Miller TW, editor. Nutrition through the life span: needs and health concerns in critical periods. Lexington: Springer New York: 2010.

26. Brown JE. Nutrition through the life cycle. Cengage Learning, 5th Edition. Stanford; 2013. Pages 37, 257-508.

27. Assefa S, Mossie A, Hamza L. Prevalence and severity of anemia among school children in Jimma Town, Southwest Ethiopia. BMC Hematology. 2014;14:3.

28. Chankanka O, Marshall TA, Levy SM, Warren JJ, Broffitt MB, et al. Mixed dentition cavitated caries incidence and dietary intake frequencies. Pediatr Dent. 2011;33:233.

29. Gupta S, Taraphdar P, Roy TG, Haldar D, Dey SK, et al. The silent burden of anemia in school age children: a community based study in West Bengal. Indian J Med Sci. 2012;66:163

30. Jennings A, Welch A, van Sluijs EMF, Griffin SJ, Cassidy A. Diet quality is independently associated with weight status in children aged 9-10 years. J Nutr. 2011;141:453-9.

31. Boeing $H$, Bechthold A, Bub A, Ellinger $S$, Haller D, et al. Critical review: vegetables and fruit in the prevention of chronic diseases. Eur J Nutr. 2012;51:637-63
32. Kaikkonen J, Mikkilä V, Raitakari O. Role of childhood food patterns on adult cardiovascular disease risk. Curr Atheroscler Rep. 2014;16:1-15.

33. Cespedes EM, Hu FB. Dietary patterns: from nutritional epidemiologic analysis to national guidelines. Am J Clin Nutr. 2015;101:899-900.

34. Galbete C, Nicolaou M, Meeks KA, de -Graft Aikins A, Addo J, et al. Food consumption, nutrient intake, and dietary patterns in Ghanaian migrants in Europe and their compatriots in Ghana. Food Nutr Res. 2017;61:1341809.

35. Frank LK, Kröger J, Schulze MB, Bedu-Addo G, Mockenhaupt FP, et al. Dietary patterns in urban Ghana and risk of type 2 diabetes. Br J Nutr. 2014; 112:89-98.

36. Doku D, Koivusilta L, Raisamo S, Rimpelä A. Socio-economic differences in adolescents' breakfast eating, fruit and vegetable consumption and physical activity in Ghana. Public Health Nutr. 2013;16:864-72.

37. Buxton CNA. Ghanaian junior high school adolescents dietary practices and food preferences: implications for public health concern. J Nutr Food Sci. 2014:4:1.

38. Peltzer K, Pengpid S. Overweight and obesity and associated factors among school-aged adolescents in Ghana and Uganda. Int J Environ Res Public Health. 2011:8:3859-70.

39. Thompson FE, Byers T. Dietary assessment resource manual. J Nutr. 1994; 124:2245S-318S.

40. Aryeetey R, Lartey A, Marquis GS, Nti H, Colecraft E, et al. Prevalence and predictors of overweight and obesity among school-aged children in urban Ghana. BMC Obes. 2017;4:38.

41. Shorr IJ. How to weigh and measure children. 1986.

42. Filmer D, Pritchett LH. Estimating wealth effects without expenditure data-or tears: an application to educational enrollments in states of India* Demography. 2001;38:115-32.

43. De Onis M, Blössner M. Prevalence and trends of overweight among preschool children in developing countries. Am J Clin Nutr. 2000;72:1032.

44. Kaiser HF. The application of electronic computers to factor analysis. Educational and psychological measurement. 1960;20(1):141-151.

45. Popkin BM. Global nutrition dynamics: the world is shifting rapidly toward a diet linked with noncommunicable diseases. Am J Clin Nutr. 2006;84:289.

46. Odegaard AO, Koh WP, Yuan J-M, Gross MD, Pereira MA. Western-style fast food intake and cardio-metabolic risk in an eastern country. Circulation. 2012:126:182-8. CIRCULATIONAHA. 111.084004

47. Pala V, Lissner L, Hebestreit A, Lanfer A, Sieri S, et al. Dietary patterns and longitudinal change in body mass in European children: a follow-up study on the IDEFICS multicenter cohort. Eur J Clin Nutr. 2013;67:1042-9.

48. Craig LC, McNeill G, Macdiarmid Jl, Masson LF, Holmes BA. Dietary patterns of school-age children in Scotland: association with socio-economic indicators, physical activity and obesity. Br J Nutr. 2010;103:319-34.

49. Richter A, Heidemann C, Schulze MB, Roosen J, Thiele S, et al. Dietary patterns of adolescents in Germany-associations with nutrient intake and other health related lifestyle characteristics. BMC Pediatr. 2012;12:35.

50. Corrêa RS, Vencato PH, Rockett FC, Bosa VL. Dietary patterns: are there differences between children and adolescents? Ciência \& Saúde Coletiva. 2017;22:553-62.

51. Johnson L, Mander AP, Jones LR, Emmett PM, Jebb SA. Energy-dense, lowfiber, high-fat dietary pattern is associated with increased fatness in childhood. Am J Clin Nutr. 2008:87:846-54.

52. Jackson EA, Eagle T, Leidal A, Gurm R, Smolarski J, et al. Childhood obesity: a comparison of health habits of middle-school students from two communities. Clin Epidemiol. 2009;1:133.

53. Monteiro CA, Moura EC, Conde WL, Popkin BM. Socioeconomic status and obesity in adult populations of developing countries: a review. Bull World Health Organ. 2004:82:940-6.

54. Amfo-Ayeh S. Food environments in basic schools in the Ga-East municipality. Accra: School of Public Health, University of Ghana, Legon; 2011.

55. Lund EK. Health benefits of seafood; is it just the fatty acids? Food Chem. 2013;140:413-20.

56. Colecraft E, Marquis GS, Aryeetey R, Sakyi-Dawson O, Lartey A, et al. Constraints on the use of animal source foods for young children in Ghana: a participatory rapid appraisal approach. Ecol Food Nutr. 2006;45:351-77.

57. Shim J-S, Oh K, Kim HC. Dietary assessment methods in epidemiologic studies. Epidemiol Health. 2014;36:e2014009. 